\title{
Non-occupational malignant pleural mesothelioma due to asbestos and non-asbestos fibres
}

\author{
L. Proietti1, L. Spicuzza22, A. Di Maria², R. Polosa2, \\ E. Sebastian Torres², V. Asero², G.U. Di Maria²
}

ABSTRACT: Non-occupational malignant pleural mesothelioma due to asbestos and non-asbestos fibres. L. Proietti, L. Spicuzza, A. Di Maria, R. Polosa, E. Sebastian Torres, V. Asero, G.U. Di Maria.

Background and aim. The occurrence of malignant pleural mesothelioma (MPM) has been reported among population groups with no documented professional exposure to asbestos fibres living in different geographic areas. This paper reviews existing data related to non occupational MPM including its occurrence in the province of Catania (Sicily, Italy).

Methods. An electronic search of literature related to non occupational MPM was performed including the year 2005.

Results. Non occupational MPM in subjects living in areas contaminated by a variety of asbestos and non asbestos fibres has been well documented through a number of epidemiologic studies including cases series, case-control studies, and a cohort study. In addition, the observation of familial clustering of MPM, suggests that genetic factors may play a role in the pathogenesis of this malignancy. The epidemiological evidence also suggests that MPM may occur as a result of the interaction between environmental carcinogens, genetic factors, and virus infection.

Conclusion. It is likely that genetic predisposition and non-occupational exposure to low doses of asbestos and asbestos-like fibres may concur to the development of malignant mesothelioma. However, additional epidemiological and laboratory studies are needed to further understand the relationship between environmental exposure and individual susceptibility to this malignancy. Monaldi Arch Chest Dis 2006; 65: 4, 210-216.

Keywords: Asbestos fibres, non-asbestos fibres, malignant pleural mesothelioma, environmental exposure, tremolite, crocidolite, erionite, fluoro-edenite, crysotil.

1 Dipartimento di Medicina Interna e Patologie Sistemiche - Sezione di Medicina del Lavoro, Università di Catania,

2 Dipartimento di Medicina Interna e Medicina Specialistica - Sezione di Malattie Respiratorie, Università di Catania, Azienda Ospedaliera Garibaldi, Unità Operativa Complessa di Clinica Pneumologica, Catania, Italy.

Correspondence: Lidia Proietti, M.D., Professor of Occupational Medicine; Via C. Claudiano 14, 95126 Catania, Italy; e-mail: proietti@unict.it

The incidence of malignant pleural mesothelioma (MPM), one of the most aggressive and yet incurable human malignancy that was virtually unknown until the second half of the $20^{\text {th }}$ century, has rapidly increased due to the widespread mining and industrial use of asbestos in many western countries $[1,2]$. The causal relationship between asbestos exposure and MPM has been proven by a number of epidemiologic surveys, case reports, and experimental studies [3-12]. Despite the International Agency for Research on Cancer having acknowledged the carcinogenic effect of asbestos on the basis of previous studies [13-15], in Italy the use of this mineral was definitively prohibited from 1992, whereas other European countries have adopted measures to drastically decrease the use asbestos throughout Europe [16]. Thus occupational exposure to asbestos has been highlighted as the main cause of MPM in humans [17-18], although this causative link in some instances may be hardly recognised due to the long latency period between exposure and the clinical oc- currence of mesothelioma that in individual cases is up to 30-40 years after the initial exposure [19]. More recently, the importance of inadvertent exposure to asbestos fibres in urban and extra-urban areas has been emphasised [20-22].

A number of sources of asbestos in the ordinary life environment may be identified including road vehicle traffic and indoor pollution in public buildings or private houses. In the domestic environment, asbestos can be found in various house utilities, such as stoves, electrical appliances, and insulation materials. Other sources of pollution can derive from the demolition and removal of materials containing asbestos, the erosion of roof tiles, shelters, or the release of asbestos from the water supply pipeline [20-22]. However, although putative asbestos exposure of human beings has been described not only in polluted areas, but also in the ice of Greenland [23], the risk of pleural mesothelioma from non-occupational exposure to environmental asbestos has not been fully characterised. 
The aim of this paper is to quantitatively describe the occurrence of MPM due to environmental, and non-occupational exposure to asbestos or asbestos-like fibres in the general population. In order to pursue this objective we conducted a systematic review of the published medical literature on this topic.

\section{Methods}

A comprehensive electronic search of the literature (1960 to December 2005) pertinent to pleural mesothelioma due to non occupational exposure was performed by using the most important databases for medical literature including PubMed (http://www.ncbi.nlm.nih.gov/entrez/query.fcgi) and HighWire (http://www.highwire.stanford.edu/). To carry out the searches we used the exploded MeSH terms asbestos and mesothelioma combined with pleural mesothelioma, malignant pleural mesothelioma, asbestos-like fibres, asbestos exposure, environmental exposure, non-occupational exposure, domestic exposure, and contaminated soil and housing. To supplement electronically derived information, we also searched the reference lists of related reviews and original articles for relevant epidemiologic studies and case reports. The search was further limited to experimental animal studies and animal models of mesothelioma.

Four reviewers (LP, ADM, EST and VA) independently examined the titles and abstracts of all identified papers to confirm fulfilment of inclusion criteria. They recorded the paper characteristics independently by using a pre-designed data abstraction form. No disagreements occurred among reviewers on the data extracted.

\section{Results}

The initial search identified 174 studies of potential interest including 15 non-English language articles. After title and abstract review, 90 studies were excluded. Of 84 studies meeting the initial inclusion criteria, 41 were accepted for data abstraction. This analysis allowed us to identify 17 geographical areas whose populations were at risk for the onset of MPM related to the exposure to asbestos and non-asbestos fibres in their daily living environment (table 1).

In 1960 Wagner and co-workers [15] described cases of malignant mesothelioma among individuals who had neither worked in extraction industries of South Africa nor were assigned to the selection or transportation of asbestos.

A systematic review of the death certificates listing the usual occupation and industrial activity of 487 mesothelioma deaths recorded in Wisconsin from 1959 to 1989 identified 41 persons with likely exposure to asbestos-containing building materials (ACBM), leading to the conclusion that individuals occupationally exposed to in-place ACBM are at risk for the subsequent development of mesothelioma [24].
In 1978 the epidemic MPM was described among the population of Karain, a small village $300 \mathrm{~km}$ south-east of Ankara, due to erionite, a particular zeolite, that were present in the local rocks and used to build houses and road floors [25-26].

In 1987 McKonnochie reported cases of MPM due to environmental pollution by tremolite in Cyprus [27]. In the same year Langer and coworkers also reported cases of MPM due to the high concentration of tremolite in the white plaster used in the construction of houses in the North West of Greece [28]. In 1991 Golberg and coworkers recorded and compared with five cancer registers all cases of primary pleural cancers that were reported during a 10-yrs period (i.e. 19781987) in New Caledonia. They found that there was an excess of primary pleural cancers in the area of New Caledonia that was particularly evident among the Melanesian ethnic group [29].

In 1992, five cases of MPM were described in a rural population of Macedonia, Greece. A high content of asbestos (chrysotile and tremolite) up to $90 \%$ by volume was subsequently found in the material used for whitewashing the houses up to 1935 [30].

Rey and co-workers in 1993 reported 14 cases of MPM due to environmental pollution by tremolite in the north east of Corsica [31].

In some parts of rural Anatolia, central Turkey, it has been shown that environmental exposure to asbestos due to the use of asbestos-contaminated soil mixtures was associated to an increased risk of MPM in these rural regions [32-33].

Cases of MPM due to environmental pollution, rather than occupational exposure, have been described in the town of Biancavilla in Eastern Sicily [34]. In 1996 for the first time data on mortality due to MPM in this town was provided [35], showing a significant local increase in mortality due to MPM between 1988 and 1992. According to official statistical data in Italy, the prevalence of MPM in this area significantly increased in the period between 1993 and 1997. In this area there was no occupational risk and consequently the population was exposed to mineral fibres present in a stone cave located immediately outside the town [3637]. This fibres, previously found in a Japanese volcano [38], is a yellowish and grey-whitish asbestos-like amphiboles with strongly asymmetric morphology, identified as fluoro-edenite, that had been traced in lung tissue from a patient who died as a result of pleural mesothelioma in 2001.

In the population living in the area of Broni (Pavia, Italy), an increased mortality rate for malignant pleural neoplasms was reported in both genders in 1980 to 1997 , compared to the general population. However, this high death rate was attributed to the presence of an asbestos-cement factory in that area rather than to environmental exposure [39].

Another example of MPM due to exposure to environmental contamination is provided by a study conducted among the population living in the area of Casale Monferrato. This study confirms the association of environmental asbestos expo- 
sure and MPM, after careful control for other sources of asbestos exposure, and suggests that in Casale Monferrato, environmental exposure caused a greater risk than domestic exposure [40].

A multi-centre study conducted in some Italian areas, in Spain and in Switzerland, to assess the effect of the environmental exposure to asbestos, has established the risk of exposure among 53 cases of mesothelioma and 232 controls who had never been exposed. Compared to controls, the study showed a relative risk of 2.2 for low exposure, 9.5 for intermediate exposure and 45.0 for high level exposure [41].

Camus and co-workers in their study on the risk of lung cancer due to non-occupational exposure to chrysotile asbestos in mining areas in the province of Quebec, Canada, found that the relative risk of death for pleural cancer was 7.63 [42]. Similarly, in the Wittenoom residents' cohort study, it was observed that the proximity of a crocidolite industry was associated with a dose-dependent increase in the risk of mesothelioma among people not directly employed in industrial activity [43].

In Lucania, Italy, in the towns of Lauria and Castelluccio Superiore, between 1998 and 2002, 3 cases of non-occupational pleural mesothelioma were identified, and possible asbestos pollution sources sought. Pollution from asbestos manufactured articles was excluded, whereas in three subsequent campaigns of collecting and chemicalmineralogical investigations the presence of "green stones", which had always been known to the local inhabitants, was highlighted. These stones resulted to be partly constituted by amphibole asbestos classified as tremolite [44, 45].

Recently, we observed cases where there was an occurrence of MPM in housewives living in the province of Catania [46]. Therefore, in order to assess one or more potential risk factors, we retrospectively reviewed clinical records of all patients with diagnosis of MPM made in our hospital between April 1999 and December 2002. A total of 24 patients were reviewed, all were residents in the area of Catania. For all male patients occupational or environmental exposure to asbestos was documented, whereas for the 7 women either occupational or environmental exposure could not be shown. In addition, none of the women had lived with a partner who had been exposed to asbestos, or had been exposed to ionizing radiation or had a smoking history. Although the etiology of mesothelioma in these women remains unknown, it is likely that an individual genetic susceptibility could have determined the disease in response to a low environmental exposure to asbestos or asbestos-like fibres. A recent review on mesothelioma and low dose exposure was unable to demonstrate a threshold level below which there is no risk of disease occurrence [47]. Some observational studies conducted in the villages of Karain and Tuzkoy, in Anatolia, Turkey, revealed the existence of an individual genetic predisposition to mesothelioma [48]. The authors of this observation constructed a genetic-epidemiology map to test whether or not some villagers were genetically predisposed. Analysis of a six-generation extended pedigree of 526 individuals showed that the susceptibility to mesothelioma was genetically transmitted, likely in an autosomal dominant way. Erionite, that was present in stones used to build the villages of Karain and Tuzkoy (zeolite villages), had been mined from nearby caves and was supposed to be the cause of mesothelioma in a relevant proportion of villagers. Measurable levels of airborne erionite fibres were detected in houses, annexes, and streets of those villages. Zeolite is a non-asbestos mineral, which has been identified as the fibrous zeolite, erionite. The diagnosis of MPM was made histologically and confirmed through electron microscopy and immunohistochemistry. It has been demonstrated that both as-

Table 1. - Geographical areas naturally contaminated with asbestos or asbestos-like fibres identified throughout the literature search

\begin{tabular}{llcl}
\hline Contaminating fibre type & \multicolumn{1}{c}{ Geographic area } & Year of first report & Refs. \\
\hline Tremolite & Bulgaria & 1970 & 59 \\
Tremolite, chrysotile & Turkey (South-east) & 1976 & 60,61 \\
Erionite & Turkey (Central Cappadocia) & 1978 & $25,26,77,78,82,83$ \\
Tremolite & Greece (Metsovo) & 1981 & $28,66,80,81$ \\
Tremolite, chrysotile & Cyprus & 1987 & 23,27 \\
Crocidolite & Cina (Da-yao) & 1990 & 62,73 \\
Tremolite & New Caledonia (South Pacific) & 1991 & $29,69,72$ \\
Chrysotile, tremolite & Greece (various area) & 1991 & 68 \\
Chrysotile, tremolite & Corsica & 1991 & 31,79 \\
Chrysotile, tremolite & Greece (Macedonia) & 1992 & 30 \\
Tremolite & Afganistan & 1994 & 63 \\
Tremolite & Botswana & 2000 & 65 \\
Tremolite, actinolite & Turkey (Southern Anatolia) & 2000 & 64 \\
Fluoro-edenite & Italy (Sicily) & 2000 & $34,36,37,75,76$ \\
Tremolite & Italy (Piedmont) & 2002 & 67,74 \\
Actinolite, tremolite & Turkey (Anatolia) & 2002 & $32,33,48,49,58$ \\
Tremolite & Italy (Basilicata) & 2003 & 44,45 \\
\hline
\end{tabular}


bestos and erionite cause a variety of benign and malignant chest diseases. Among the diseases, calcified pleural plaques (CPP) are the most frequently seen and may be used as an indicator of mineral fibre exposure [49].

\section{Discussion}

The results of this search show that in the last thirty years clusters of pleural mesothelioma have been reported in populations with non-professional environmental exposure to asbestos - mainly tremolite - and other mineral fibres, including erionite and fluoro-edenite, contaminating soils, roads and buildings of various geographical areas. Industrial sources of hazardous mineral fibres were not identified in any of the areas listed in table 1. However, despite this evidence - mostly circumstantial - none of the published reports has determined the level and duration of exposure representing a significant risk for subjects living in a given area. The intensity of environmental non-occupational exposure can vary according to a number of individual and environmental factors. In addition, the physical characteristics of mineral fibres and the individual susceptibility of exposed subjects might also influence causal relationships. The risk of developing asbestos-related MPM depends on the dose, dimensions, surface reactivity and biopersistence of inhaled materials. Thus the magnitude of risk for the inhabitants of naturally contaminated areas remains undetermined.

Taking into account the epidemiological data and the long latency period between exposure and the occurrence of mesothelioma one could expect that the banning of asbestos will not result in a rapid decrease of related health problems. More than 30 million tons of asbestos in its various forms have been mined and used in a variety of manufacturing activity throughout the world in the past century. Peto and colleagues using an age/birth group model to calculate the number of male deaths from pleural mesothelioma for six countries in Western Europe including Great Britain, France, Italy, Germany, The Netherlands, and Switzerland, predicted that the annual death rates from mesothelioma will increase from 5,000 up to 9,000 between 1998 and 2018, after which a decline is expected [50]. According to these authors, the highest risk will be suffered by male subjects born around 1945-50.

The causal relationship between asbestos or asbestos-like fibres and mesothelioma either in workers exposed in the workplace or in subjects living in areas polluted by the presence of asbestos extraction facilities and manufacturing has been well documented by several studies, and it has been reported in cases series, case-control and cohort studies.

The link between asbestos and MPM has been firmly established, and the great majority of mesothelioma are caused by asbestos and most of them are due to occupational rather than environmental exposure [51]. The different types of asbestos seem to differ considerably in their ability to cause pleural neoplasms. Chrysotile is considered by many authors to be a weak carcinogen in humans, [51], whereas it is well known that the amphiboles crocidolite and tremolite seems to be much more dangerous [52]. Nevertheless, to date the mechanism of asbestos carcinogenicity, the causal role of chrysotile asbestos compared with crocidolite and tremolite in the genesis of MPM [51-52], the amount of asbestos necessary to cause MPM, remain unclear and are still being debated by many authors. Furthermore, several studies [4649, 53-57] suggest that genetic factors may play a more important role in the etiology of this disease than currently appreciated. The interplay of genes and environment in the pathogenesis of MPM requires further elucidation. Additional epidemiological and laboratory studies are needed to provide a better understanding of the relationship between environmental carcinogen mineral fibres and genetics and viruses.

The most frequent naturally contaminating material in our review was tremolite asbestos. It occurred in 14 out of the 17 areas identified (table 1). In contrast non-asbestos fibrous materials such as erionite and fluoro-edenite were less frequently found. More recently, attention has been paid to the outbreak of mortality from MPM recorded in the population of Biancavilla (Sicily, Italy) in the late eighties-early nineties [35]. This was subsequently attributed to the non-occupational exposure to fluoro-edenite, the new fibrous amphibole end-member found in the inert material extracted from a nearby quarry located in "Monte Calvario" in the Etna volcanic complex. This mineral had been already found in another volcanic setting [38], and later characterised [84].

The interpretation of epidemiological studies aimed at unravelling disease etiology revolves around the question of whether or not there is a causal association between a putative risk factor and the disease under study. Whereas the association between exposure to tremolite and mesothelioma either in the workplace or in the daily life environment is clear, for all new members of the amphibole family collaborative epidemiologic, environmental, and experimental studies are necessary to determine if they are the true cause of the disease under investigation. Interestingly, in the municipality of Biancavilla, along with the unexpected increase in death rate from non-occupational mesothelioma, an increased mortality due to chronic obstructive pulmonary disease (COPD) was observed, suggesting that fluoro-edenite might also have a role in the etiology of non-malignant respiratory diseases [76]. This possibility is indirectly supported by the results of a recent toxicity study showing that fluoro-edenite fibres alter the cellular tropism and increase the production of pro-inflammatory cytokine IL-6 in pulmonary epithelial cells in vitro [85]. Conflicting with this evidence, a mineralogical website states that for this mineral there is no specific data on health dangers or toxicity [86].

Taken together the data obtained from our literature review suggests that despite the banning of 
asbestos from industrial activity, naturally occurring mineral fibres will probably be at stake as cause of pleural malignancy and other respiratory disorders in the near future. The principal aim in public health care should be the prevention of environmental exposure to asbestos and asbestos-like fibres, educating to avoid use of asbestos-contaminated materials for whitewashing, and wall plastering. Whenever possible, potential sources of contamination from previously known or newly discovered mineral fibres should be carefully localised and adequately contained. These measures will not only limit the dispersion of fibres in adjacent areas but also prevent the inadvertent transport of fibres to more distantly located sites and avoid construction-related contamination of roads and buildings.

Acknowledgements: We wish to express our gratitude to Dr. Pietro Comba and the Environmental Epidemiology Department of the Istituto Superiore di Sanità, Rome, Italy, for their valuable advice to our search and analysis of data. We are also indebted to Dr. Pietro Comba for revising the manuscript and for his helpful comments.

\section{References}

1. Tossavainen A. National mesothelioma incidence and the past use of asbestos. Monaldi Arch Chest Dis 2003; 59: 146-149.

2. Peto J, De Carli A, La Vecchia C, Levi F, Negri E. The European mesothelioma epidemic. Br J Cancer 1999; 79: 666-672.

3. Selikoff IJ, Churg J and Hammond EC. Relation between exposure to asbestos and mesothelioma. New Engl J Med 1965; 272: 560-565.

4. Mossman BT, Gee JB. Asbestos-related diseases. N Engl J Med 1989; 320: 1721-1730.

5. Driscoll R, Mulligan WJ, Schultz, et al. Malignant mesothelioma. A cluster in a native American pueblo. New Engl J Med 1988; 318: 1437-1438.

6. Shepherd KE, Oliver LC, Kazemi H. Diffuse malignant pleural mesothelioma in an urban hospital; clinical spectrum and trend in incidence over time. Am J Ind Med 1989; 16: 373-383.

7. Kazemi H, Mark EJ. Clinico-Pathologic Conference. New Engl J Med 1990; 323: 659-667.

8. Churg A. Chrysotile, tremolite, and malignant mesothelioma in man. Chest 1988; 93: 621-628.

9. Pisani RJ, Colby TV, Williams DE. Malignant mesothelioma of the pleura. Mayo Clin Proc 1988; 63: 1234-1244.

10. Hillerdal G. Pleural malignancies including mesothelioma. Curr Opin Pulm Med 1995; 1: 339-343.

11. Metintas M, Hillerdal G, Metintas S. Malignant mesothelioma due to environmental exposure to erionite: follow-up of a Turkish emigrant cohort. Eur Respir $J$ 1999; 13: 523-526.

12. Grondin SC, Sugarbaker DJ. Malignant mesothelioma of the pleural space. Oncology 1999; 13: 919-926.

13. IARC monographs on the evaluation of carcinogenic risks of chemicals to humans. Vol 1 (Asbestos). Lyon, 1973.

14. Doll R. Mortality from lung cancer in asbestos workers. Br J Ind Med 1955; 12: 81-86.

15. Wagner JC, Sleggs, CA, Marchand P. Diffuse pleural mesothelioma and asbestos exposure in the North Western Cape Province. Br J Ind Med 1960; 17: 260-271.

16. European Communities. Commission Directive 1999/77/EC (1999) on the marketing and use of certain dangerous substances and preparation (asbestos), European Commission, Brussels, 1999

17. Mirabelli D, Magnani C. Interazione tra l'esposizione lavorativa ed ambientale ad amianto. Indagini epidemiologiche. G Ital Med Lav Erg 2003; 25: 361-379.

18. McDonald JC, Sebastien P, McDonald AD, Case B Epidemiological observations on mesothelioma and their implications for non-occupational. IARC Sci Publ 1989; 90: 420-427.

19. Selikoff IJ, Hammond EC. Asbestos-associated disease in United States shipyards. CA Cancer J Clin 1978; 28 : 87-99.

20. Landrigan PJ. The third wave of asbestos disease: exposure to asbestos in place. Public health control. Introduction. Ann N Y Acad Sci 1991; 643: xv-xvi.

21. Molloy LB. Asbestos in place in Metropolitan New York. Ann N Y Acad Sci 1991; 643: 614-21.

22. Pasetto R, Comba P, Marconi A. Mesothelioma associated with environmental exposures. Med Lav 2005; 96: 330-337.

23. Hillerdal G. Mesothelioma: cases associated with nonoccupational and low dose exposures. Occup Environ Med 1999; 56: 505-513.

24. Anderson HA, Hanrahan LP, Schirmer J, Higgins D, Sarow P. Mesothelioma among employees with likely contact with in-place asbestos-containing building materials. Ann N Y Acad Sci 1991; 643: 550-572.

25. Baris YI, Sahin AA, Ozesmi M, et al. An outbreak of pleural mesothelioma and chronic fibrosing pleurisy in the village of Karain/Urgup in Anatolia. Thorax 1978; 33: 181-192.

26. Baris YI, Saracci R, Simonato L, Skidmore JW, Artvinli M. Malignant mesothelioma and radiological chest abnormalities in two villages in Central Turkey. An epidemiological and environmental investigation. Lancet 1981; 1 (8227): 984-987.

27. McConnochie K, Simonato L, Mavrides P, Christofides P, Pooley FD, Wagner JC. Mesothelioma in Cyprus: the role of tremolite. Thorax 1987; 42: 342-347.

28. Langer AM, Costantopoulos SH, Nolan RP, Moutsopoulos HM. Association of Metsovo lung and pleural mesothelioma with exposure to tremolite-containing whitewash. Lancet 1987; 25: 965-967.

29. Goldberg P, Goldberg M, Marne MJ, Hirsch A, Tredaniel J. Incidence of pleural mesothelioma in New Caledonia: a 10-year survey (1978-1987). Arch Environ Health 1991; 46: 306-309.

30. Sichletidis L, Daskalopoulou E, Tsarou V, Pnevmatikos I, Chloros, D, Vamvali C. Five cases of pleural mesothelioma with endemic pleural calcifications in a rural area in Greece. Med Lav 1992; 83: 326-329.

31. Rey F, Boutin C, Steinbauer J, et al. Environmental pleural plaques in an asbestos exposed population of Northeast Corsica. Eur Respir J 1993; 6: 978-982.

32. Metintas M, Ozdemir N, Hillerdal, et al. Environmental asbestos exposure and malignant pleural mesothelioma. Respir Med 1999; 93: 349-355.

33. Metintas S, Metintas M, Ucgun I, Oner U. Malignant mesothelioma due to environmental exposure to asbestos: follow-up of a Turkish cohort living in a rural area. Chest 2002; 122: 2224-2229.

34. Paoletti L, Batisti D, Bruno C, et al. Unusually high incidence of malignant pleural mesothelioma in a town of eastern Sicily: an epidemiological and environmental study. Arch Environ Health 2000; 55: 392-398.

35. Di Paola M, Mastrantonio M, Carboni M, et al. La mortalità per tumore maligno della pleura in Italia negli anni 1988-1992. In Istituto Superiore di Sanità (eds): Rapporti ISTISAN 96/40. Roma 1996; 1-30.

36. Manna P, Comba P. Comunicazione con le autorità sanitaria e con il pubblico sui rischi da amianto a Biancavilla (CT). Epidemiol Prev 2001; 25: 28-30. 
37. Proietti L, Rapisarda V, Giarrusso S, D’Antona C, Valentino M, Duscio D. Mortalità per mesotelioma pleurico nel periodo 1988-1998 nei residenti di un comune etneo: studio epidemiologico. Atti $65^{\circ}$ Congresso SIMLII. Messina-Naxos. G Ital Med Lav Erg 2003; 25: 2.

38. Makino K, Yamaguchi Y, Tomita K. Fluoredenite from the Ishigamiyama lava dome of the Kimpo Volcano, Kumamoto, Southwest Japan. GANKO 1996; 91: 419-423.

39. Amendola P, Belli S, Binazzi A, et al. Mortality from malignant pleural neoplasms in Broni (Pavia), 19801997. Epidemiol Prev 2003; 27 86-90.

40. Magnani C, Dalmasso P, Biggeri A, Ivaldi C, Mirabelli D, Terracini B. Increased risk of malignant mesothelioma of the pleura after residential or domestic exposure to asbestos: a case-control study in Casale Monferrato, Italy. Environ Health Perspect 2001; 109: 915919.

41. Magnani C, Agudo A, Gonzalez CA, et al. Multicentric study on malignant pleural mesothelioma and non-occupational exposure to asbestos. Br J Cancer 2000; 83: 104-111.

42. Camus M, Siemiatycki J, Meek B. Nonoccupational exposure to chrysotile asbestos and the risk of lung cancer. N Engl J Med. 1998; 338: 1565-1571.

43. Hansen J, de Klerk NH, Musk AW, Hobbs MS. Environmental exposure to crocidolite and mesothelioma: exposure-response relationships. Am J Respir Crit Care Med 1998; 157: 69-75.

44. Pasetto R, Bruni B, Bruno C, et al. Pleural mesothelioma and environmental exposure to mineral fibres: the case of a rural area in the Basilicata region, Italy. Ann Ist Super Sanità 2004; 40: 251-265.

45. Bernardini P, Schettino B, Sperduto B, Giannandrea F, Burragato F, Castellino N. Tre casi di mesotelioma pleurico ed inquinamento ambientale. G Ital Med Lav Erg 2003; 25: 408-411

46. Proietti L, Migliore M, Polosa R, Comba P, Circo C, Di Maria GU. Pleural malignant mesothelioma in housewife in Catania area. Recenti Prog Med 2004; 95: 365368.

47. Hillerdal G. Mesothelioma: cases associated with nonoccupational and low dose exposures. Occup Environ Med 1999; 56: 505-513.

48. Roushdy-Hammady I, Siegel J, Emri S, Testa JR, Carbone M. Genetic-susceptibility factor and malignant mesothelioma in the Cappadocian region of Turkey. Lancet 2001; 357 (9254): 444-445.

49. Emri S, Demir A, Dogan M, et al. Lung diseases due to environmental exposures to erionite and asbestos in Turkey. Toxicol Lett 2002; 127: 251-257.

50. Peto J, Decarli A, La Vecchia C, Levi F, Negri E. The European mesothelioma epidemic. Br J Cancer 1999; 79: 666-672.

51. Gibbs AR, Griffiths DM, Pooley FD, Jones JS. Comparison of fibre types and size distributions in lung tissues of paraoccupational and occupational cases of malignant mesothelioma. Br J Ind Med 1990; 47: 621-626.

52. Rogers AJ, Leigh J, Berry G, Ferguson DA, Mulder HB, Ackad M. Relationship between lung asbestos fiber type and concentration and relative risk of mesothelioma. A case-control study. Cancer 1991; 67: 1912-1920.

53. Ascoli V, Carnovale-Scalzo C, Nardi F, Efrati C, Menegozzo M. A one-generation cluster of malignant mesothelioma within a family reveals exposure to asbestos-contaminated jute bags in Naples, Italy. Eur $J$ Epidemiol 2003; 18: 171-174.

54. Knudson A. Asbestos and mesothelioma: genetic lessons from a tragedy. Proc Natl Acad Sci USA 1995; 92: 10819-10820.

55. Gun RT. Mesothelioma: is asbestos exposure the only cause? Med J Aust 1995; 162: 429-431.
56. Powers A, Carbone M. The role of environmental carcinogens, viruses and genetic predisposition in the pathogenesis of mesothelioma. Cancer Biol Ther 2002; 1: 348-353.

57. Di Maria GU, Comba P. Malignant pleural mesothelioma: the puzzling role of gene-environment interaction. Chest 2004; 125: 1604-1607.

58. Huncharek M. Non-asbestos related diffuse malignant mesothelioma. Tumori 2002; 88: 1-9.

59. Burlikov T, Michailova L. Asbestos content of the soil and endemic pleural asbestosis. Environ Res 1970; 3: 443-451.

60. Yazicioglu S. Pleural calcification associated with exposure to chrysotile asbestos in southeast Turkey. Chest 1976; 70: 43-47.

61. Yazicioglu S, Oktem K, Ilcayto R, Balci K, Sayli BS Association between malignant tumors of the lungs and pleurae and asbestosis. A retrospective study. Chest 1978; 73: 52-56.

62. Liu XZ, Luo SQ, Wang ZM, Wang MZ, Zhan CL. An investigation of crocidolite contamination and mesothelioma in a rural area of China. Biomed Environ Sci 1990; 3: 156-165.

63. Voisin C, Marin I, Brochard P, Pairon JC. Environmental airborne tremolite asbestos pollution and pleural plaques in Afghanistan. Chest 1994; 106: 974-976.

64. Zeren EH, Gumurdulu D, Roggli VL, Zorludemir S, Erkisi M, Tuncer I. Environmental malignant mesothelioma in southern Anatolia: a study of fifty cases. Environ Health Perspect 2000; 108: 1047-1050.

65. Khudu-Petersen K, Bard D, Garrington N, Yarwood J, Tylee B. Microscopic identification of asbestos fibres associated with African clay crafts manufacture. Ann Occup Hyg 2000 Mar; 44 (2): 137-141.

66. Bazas T, Bazas B, Kitas D, Gilson JC, McDonald JC. Pleural calcification in north-west Greece. Lancet 1981; 2 (8240): 254

67. Mirabelli D, Cadum E. Mortality among patients with pleural and peritoneal tumors in Alta Valle di Susa. Epidemiol Prev 2002; 26: 284-286.

68. Constantopoulos SH, Theodoracopoulos P, Dascalopoulos G, Saratzis N, Sideris K. Metsovo lung outside Metsovo. Endemic pleural calcifications in the ophiolite belts of Greece. Chest 1991; 99: 1158-1161.

69. Goldberg P, Luce D, Billon-Galland MA, et al. Potential role of environmental and domestic exposure to tremolite in pleural cancer in New Caledonia. Rev Epidemiol Santé Publique 1995; 43: 444-450.

70. Luce D, Bugel I, Goldberg P, et al. Environmental exposure to tremolite and respiratory cancer in New Caledonia: a case-control study. Am J Epidemiol 2000; 151: 259-265.

71. Marchand JL, Luce D, Goldberg P, Bugel I, Salomon C, Goldberg M. Dietary factors and the risk of lung cancer in New Caledonia (South Pacific). Nutr Cancer 2002; 42: $18-24$

72. Menvielle G, Luce D, Fevotte J, et al. Occupational exposures and lung cancer in New Caledonia. Occup Environ Med 2003; 60: 584-589.

73. Luo S, Liu X, Mu S, Tsai SP, Wen CP. Asbestos related diseases from environmental exposure to crocidolite in Da-yao, China. I. Review of exposure and epidemiological data. Occup Environ Med 2003; 60: 35-42.

74. Maule M, Merletti F, Mirabelli D, La Vecchia C. Spatial variation of mortality for common and rare cancers in Piedmont, Italy, from 1980 to 2000: a Bayesian approach. Eur J Cancer Prev 2006; 15: 108-116.

75. Comba P, Gianfagna A, Paoletti L. Pleural mesothelioma cases in Biancavilla are related to a new fluoroedenite fibrous amphibole. Arch Environ Health 2003; 58: 229-232.

76. Biggeri A, Pasetto R, Belli S, et al. Mortality from chronic obstructive pulmonary disease and pleural 
mesothelioma in an area contaminated by natural fiber (fluoro-edenite). Scand J Work Environ Health 2004; 30: $250-253$.

77. Selcuk ZT, Coplu L, Emri S, Kalyoncu AF, Sahin AA, Baris YI. Malignant pleural mesothelioma due to environmental mineral fiber exposure in Turkey. Analysis of 135 cases. Chest 1992; 102: 790-796.

78. Sahin AA, Coplu L, Selcuk ZT, et al. Malignant pleural mesothelioma caused by environmental exposure to asbestos or erionite in rural Turkey: CT findings in 84 patients. Am J Roentgenol 1993; 161: 533-537.

79. Viallat JR, Boutin C, Steinbauer J, Gaudichet A, Dufour G. Pleural effects of environmental asbestos pollution in Corsica. Ann N Y Acad Sci 1991; 643: 438-443.

80. Sakellariou K, Malamou-Mitsi V, Haritou A, et al. Malignant pleural mesothelioma from nonoccupational asbestos exposure in Metsovo (north-west Greece): slow end of an epidemic? Eur Respir J 1996; 9: 1206-1210.

81. Constantopoulos SH, Malamou-Mitsi VD, Goudevenos JA, Papathanasiou MP, Pavlidis NA, Papadimitriou CS.
High incidence of malignant pleural mesothelioma in neighbouring villages of Northwestern Greece. Respiration 1987; 51: 266-271.

82. Baris YI, Artvinli M, Sahin AA, Bilir N, Kalyoncu F, Sebastien P. Non-occupational asbestos related chest diseases in a small Anatolian village. $\mathrm{Br} J$ Ind Med 1988; 45: 841-842.

83. Baris YI, Bilir N, Artvinli M, Sahin AA, Kalyoncu F, Sebastien P. An epidemiological study in an Anatolian village environmentally exposed to tremolite asbestos. Br J Ind Med 1988; 45: 838-840.

84. Gianfagna A, Oberti R. Fluoro-edenite from Biancavilla (Catania, Sicily, Italy): Crystal chemistry of a new amphibole end-member. Am Mineralogist 2001; 86: 1489-1493.

85. Travaglione S, Bruni B, Falzano L, Paoletti L, Fiorentini C. Effects of the new-identified amphibole fluoroedenite in lung epithelial cells. Toxicol in Vitro 2003; 17: 547-552.

86. http: //www.mindat.org/min-6950.html

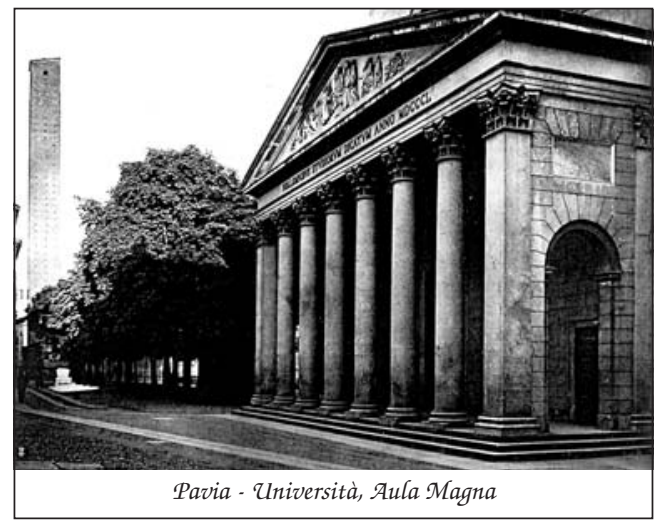

